\title{
DIFFERENT FRUCTOSE FEEDING STRATEGIES FOR POLY(3-HYDROXYBUTYRATE) PRODUCTION BYYangia sp. ND199
}

\author{
Tran Huu Phong ${ }^{1}$, Dang Minh Khuong ${ }^{2}$, Duong Van Hop ${ }^{3}$, Doan Van Thuoc ${ }^{1, *}$ \\ ${ }^{1}$ Hanoi National University of Education, 136 Xuan Thuy, Cau Giay, Hanoi, Vietnam \\ ${ }^{2}$ Bao Yen 2 High School, Bao Yen district, Lao Cai, Vietnam \\ ${ }^{3}$ Institute of Microbiology and Biotechnology, 144 Xuan Thuy, Cau Giay, Hanoi, Vietnam \\ *Email: thuocdv@hnue.edu.vn
}

Received: 8 September 2016; Accepted for publication: 24 November 2016

\begin{abstract}
Yangia sp. ND199 is a halophilic bacterium isolated from mangrove soil sample. This strain was able to produce polyhydroxyalkanoate (PHA) from different carbon sources. Only homopolymer poly(3-hydroxybutyrate) (PHB) was synthesized when fructose was used as carbon source. The bacterium could accumulate high PHB content during the exponential phase. Maximum cell dry weight (CDW) of $7.8 \mathrm{~g} / \mathrm{l}$ and PHB content of $49 \mathrm{wt} \%$ were obtained after 27 $\mathrm{h}$ of cultivation in batch fermentation. High CDW and PHB content were achieved by using fedbatch fermentation with different fructose feeding strategies. The highest CDW of $78.5 \mathrm{~g} / \mathrm{l}, \mathrm{PHB}$ content of $67.5 \mathrm{wt} \%$, and PHB productivity of $1 \mathrm{~g} / \mathrm{l} / \mathrm{h}$ were obtained by using two-stage fedbatch fermentation, is among the highest reported so far for PHB production by halophilic bacteria.
\end{abstract}

Keywords: Yangia sp. ND199, fed batch fermentation, PHB production, fructose.

\section{INTRODUCTION}

Plastic is a kind of material that is commonly used in everyday life in many forms. Most of plastics are made from petroleum oil, they are normally non-biodegradable materials. The use of petroleum-based plastics leads to big problem, because they accumulate in landfills and threaten the environment. The ecological drawbacks of petroleum-based plastics have pushed scientists to investigate and develop biodegradable plastics [1].

Polyhydroxyalkanoates (PHA) are polyester of hydroxyalkanoic acid that accumulated by various bacteria as intracellularly carbon and energy storage [1, 2]. Since first founded by Lemoigne [3], more hundred PHAs have been discovered and it's still increasing now. PHAs are thermal and elastic plastics, biocompatible, nontoxic and low immunogenicity that suitable for many applications including medical field. Biosynthesis of PHA is known to occur normally if carbon source is provided in excess while another nutrient such as nitrogen, sulfur, phosphorus, 
iron, or magnesium is limited. For PHA production, two-stage fed-batch culture is commonly used: biomass production in initial stage and PHA accumulation in second stage [2, 4].

Yangia sp. ND199 is a halophilic bacterium isolated from mangrove forest soil. The bacterium was able to produce PHA from various substrates such as glucose, fructose, glycerol, sugarcane molasses, and high fructose corn syrup [5]. Fed batch cultivation for production of poly(3-hydroxybutyrate-co-3-hydroxyvalerate) (PHBV) using pure glycerol, crude glycerol and high fructose corn syrup (HFCS) was investigated. However, the cell density was low resulted in low PHA concentration and PHA volumetric productivity [5, 6]. In order to improve cell density and PHA volumetric productivity, fed-batch fermentation with different feeding strategies was investigated.

\section{MATERIALS AND METHODS}

\subsection{Bacterial strain and media}

Yangia sp. ND199 was maintained in HM medium (medium for halophile) as described in previous studies $[5,6]$. The basal medium for fermentation in bioreactor contains $(\mathrm{g} / \mathrm{l})$ : fructose, 20; peptone, 3.0; yeast extract, $6.0 ; \mathrm{MgSO}_{4} .7 \mathrm{H}_{2} \mathrm{O}, 1.7 ; \mathrm{CaCl}_{2} .2 \mathrm{H}_{2} \mathrm{O}, 0.18 ; \mathrm{KCl}, 1.0 ; \mathrm{KH}_{2} \mathrm{PO}_{4}$, $1.1 ; \mathrm{KBr}, 0.12 ; \mathrm{NaCl}, 30$; and $1 \mathrm{ml}$ trace element solution. Trace element solution was prepared by dissolving $\mathrm{NiCl}_{2} \cdot 6 \mathrm{H}_{2} \mathrm{O}, 200 \mathrm{mg} ; \mathrm{CuSO}_{4} \cdot 4 \mathrm{H}_{2} \mathrm{O}, 100 \mathrm{mg} ; \mathrm{FeSO}_{4}, 100 \mathrm{mg} ; \mathrm{CoCl}_{2} \cdot 6 \mathrm{H}_{2} \mathrm{O}, 200$ $\mathrm{mg} ; \mathrm{H}_{3} \mathrm{BO}_{3}, 300 \mathrm{mg} ; \mathrm{Na}_{2} \mathrm{MoO}_{4}, 100 \mathrm{mg} ; \mathrm{MnCl}_{2} .4 \mathrm{H}_{2} \mathrm{O}, 200 \mathrm{mg} ; \mathrm{ZnSO}_{4} .7 \mathrm{H}_{2} \mathrm{O}, 100 \mathrm{mg}$ in one liter of water. The $\mathrm{pH}$ of medium was adjusted to 7.0 before sterilization. Fructose was separately sterilized and added to bioreactor before start the fermentation.

\subsection{Batch fermentation}

Batch fermentation was conducted in a 10 liters bioreactor (MDL-100, BE. Marusbishi, Tokyo, Japan) containing three liters of culture medium. The bacterium was cultivated in HM medium for $15 \mathrm{~h}\left(\mathrm{OD}_{600 \mathrm{~nm}} 7 \pm 0.5\right)$, after that $300 \mathrm{ml}$ seed culture was added to the bioreactor. The fermentation process was carried out at $32{ }^{\circ} \mathrm{C}, \mathrm{pH}$ was maintained at 7.0 by using $\mathrm{NaOH}(5 \mathrm{~N})$ and $\mathrm{HCl}(5 \mathrm{~N})$ as adjusted solutions. The initial agitation speed and aeration volume were set at $200 \mathrm{rpm}$ and $1 \mathrm{~L} / \mathrm{min}$, respectively. Samples were collected interval $3 \mathrm{~h}$ for cell dry weight (CDW), fructose concentration, and PHA content analysis.

\subsection{Fed-batch fermentation}

Fed-batch fermentation was carried out in $10 \mathrm{~L}$ bioreactor with three liters of initial volume. All feed solutions were prepared with similar components as basal medium above but higher concentration. For two-stage fed-batch fermentation: nitrogen-feed solution was used for first stage, and then free nitrogen solution was used for second stage. Fructose solution $(70 \%$, w/v) was prepared and sterilized separately.

The initial conditions of fermentations were set at $200 \mathrm{rpm}$ of speed and $1.5 \mathrm{~L} / \mathrm{min}$ of air. Dissolved oxygen was kept at above $20 \%$ by adjustment of speed and air flow. pH was maintained at 7.0 and controlled automatically using $5 \mathrm{M} \mathrm{NaOH} / \mathrm{HCl}$. Different fructose feeding strategies were carried out in first and second stages of fermentation process. Samples were collected interval $1.5 \mathrm{~h}$ for CDW, fructose concentration, and PHA content analysis. 


\subsection{Analytical methods}

Bacterial cells were harvested by centrifuging at $13000 \mathrm{rpm}$ for $10 \mathrm{~min}$, washed twice with distilled water, the CDW was determined after lyophilized by using Flexi Vaccum Dryer (USA). Fructose concentration was analysed offline by using p-dinitrosalysilic acid (DNS) method [7]. PHB content was determined by gas chromatography (GC) analysis. GC samples were prepared as described by Huijberts et al. [8], methyl ester was analysed using HP-7890A system (Hewlett Packard CO, USA) equipped with HP5 capillary column [9].

\section{RESULTS AND DISCUSSION}

\subsection{PHB production by batch cultivation}

Based on results of batch culture in flask experiments, batch fermentation process with three liters volume was performed in a 10 liter bioreactor. Figure 1 depicted the batch fermentation profile of strain Yangia sp. ND199. The growth curve of Yangia sp. ND199 can be divided to three phases: first $15 \mathrm{~h}$ of cultivation was the time of the exponential phase with increasing of CDW from 0.2 to $7.8 \mathrm{~g} / \mathrm{l}$, the stationary phase started from $18 \mathrm{~h}$ of cultivation, and the cells entered the death phase after $30 \mathrm{~h}$ of cultivation. The results of GC analysis indicated that Yangia sp. ND199 synthesized homopolymer poly(3-hydroxyalkanoate) (PHB) when fructose was used as carbon source. The PHB accumulation by strain Yangiasp. ND199 occurred early in batch fermentation, PHB content of $8 \mathrm{wt} \%$ was obtained after $3 \mathrm{~h}$ of cultivation and then increased to maximum value of $49 \mathrm{wt} \%$ after $27 \mathrm{~h}$ of cultivation. High fructose concentration in culture medium had trigged the PHB accumulation of this strain even there were no nutrient limitations. It means that the strain Yangia sp. ND199 can be classified to the second PHA producing bacteria group which require no such nutrient limitations for polymer accumulation [4].

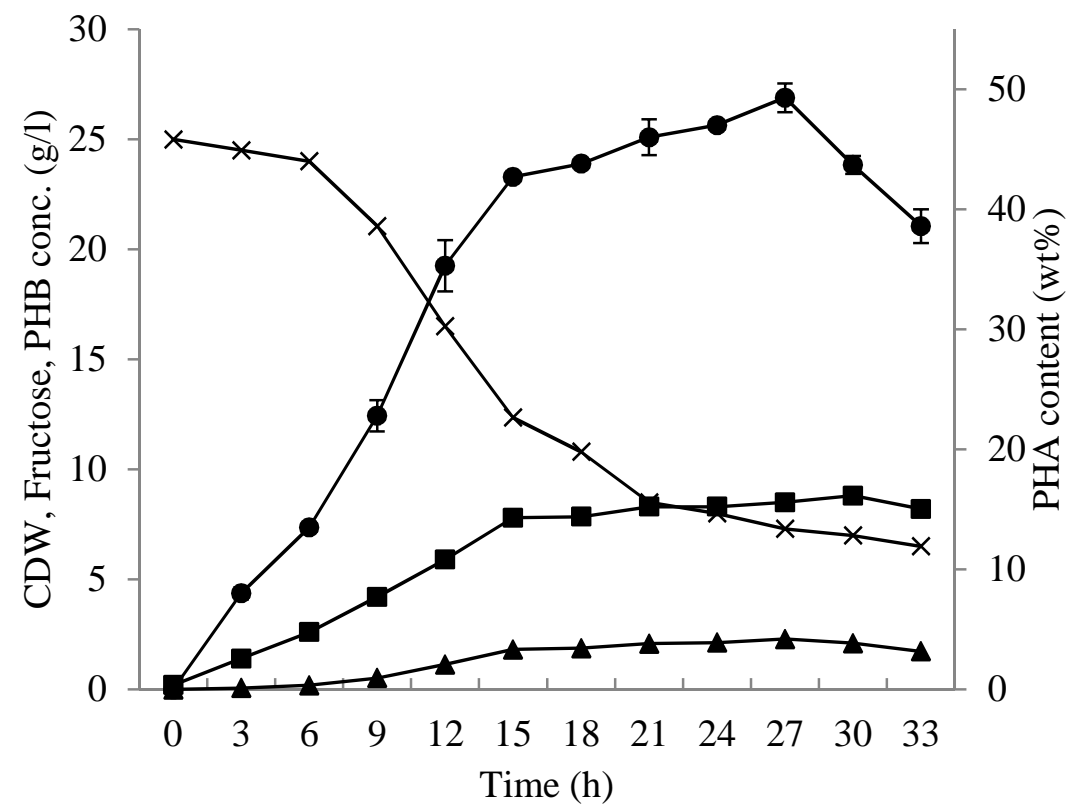

Figure 1. Batch cultivation for PHB production by Yangia sp. ND199. The symbols represent CDW $(\boldsymbol{\bullet})$, fructose $(\times)$, PHB content $(\bullet)$, and PHB concentration $(\boldsymbol{\Delta})$. 
As can be seen from the Figure 1, the rate of growth and PHB accumulation was high at the beginning of fermentation process (first $15 \mathrm{~h}$ ) when the concentration of fructose and also other nutrients in culture medium were high. After that when fructose concentration in the culture medium reduced to lower than $10 \mathrm{~g} / \mathrm{l}$, cell growth and PHA accumulation rates were decreased (Figure 1). Hence, in order to obtain high CDW and PHA content, high concentration of nutrients need to be maintained during the cultivation process. For that reason, fed-batch fermentation for PHB production by Yangia sp. ND199 was designed.

\subsection{Fed batch cultivation for PHB production by Yangia sp. ND199 with different carbon feeding strategies}

Fed-batch cultivation was conducted in $10 \mathrm{~L}$ bioreactor, fed solutions were added to the bioreactor to avoid nutrient limitations, and fructose concentration was keep around $20 \mathrm{~g} / \mathrm{L}$ during the cultivation process. The results of CDW, PHB content and PHB concentration showed in Figure 2. Maximum PHB content of $45 \mathrm{wt} \%$ was achieved after $33 \mathrm{~h}$ of cultivation, slightly lower than that obtained in batch fermentation (49 wt \% after $27 \mathrm{~h}$ of cultivation). However, CDW of $20.8 \mathrm{~g} / \mathrm{l}$ was obtained after $33 \mathrm{~h}$ of cultivation, 2.4 folds higher than that obtained in batch cultivation $(8.8 \mathrm{~g} / \mathrm{l})$. The addition of fed solutions to the culture medium helped to improve CDW. But the CDW obtained here $(20.8 \mathrm{~g} / \mathrm{l})$ is still lower than that obtained by this strain in previous study [6]. The accumulation of PHB during early stage of cultivation may inhibit the growth of bacterium because most of acetyl-CoA converts to PHB through PHB synthesis pathway, only small amount of acetyl-CoA enters to Krebs cycle for the production of ATP that need for bacterial cells growth (Figure 3). Thus change fructose concentration in medium may help to improve CDW and PHB accumulation.

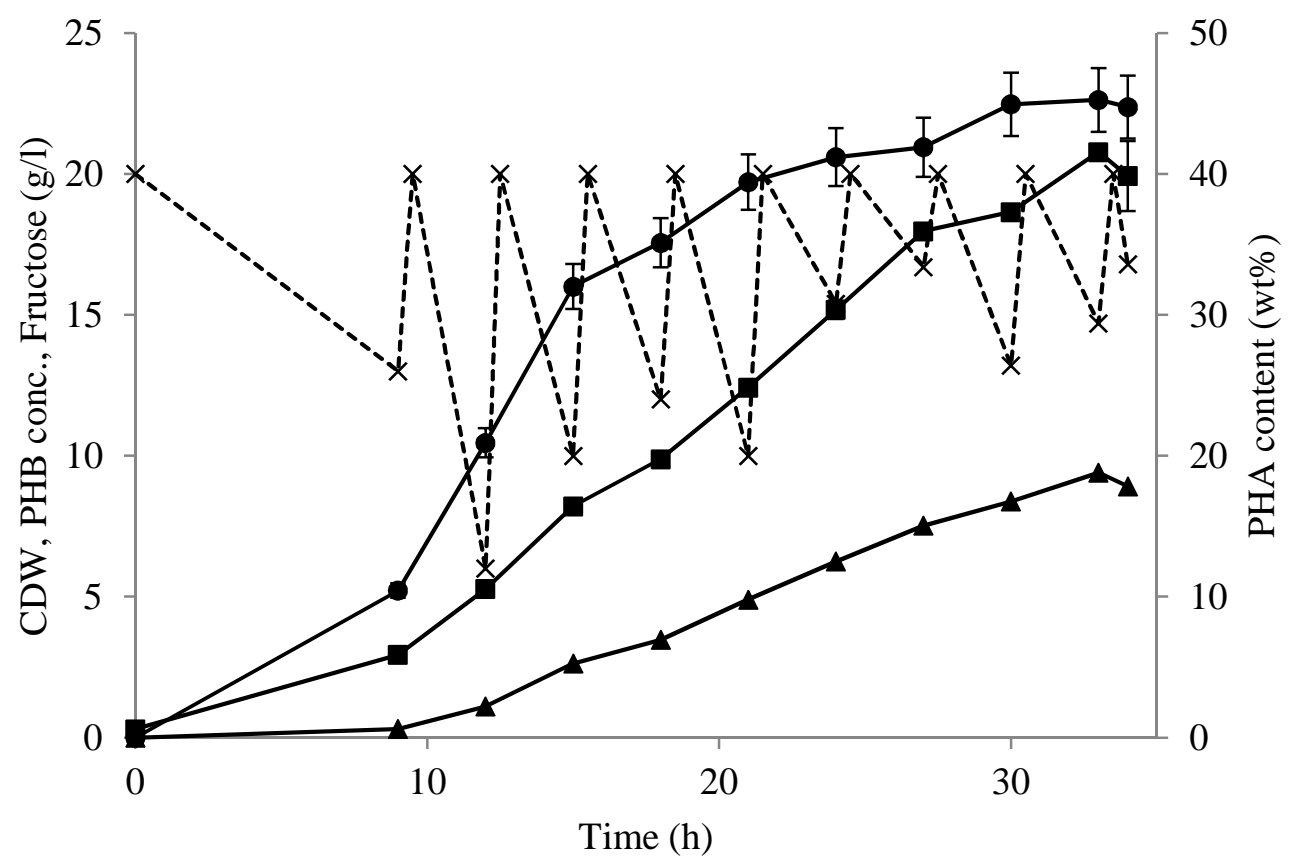

Figure 2. PHB production in fed batch fermentation with $20 \mathrm{~g} / \mathrm{l}$ of fructose. The symbols represent CDW ( $\bullet$ ), fructose $(\times)$, PHB content $(\bullet)$, and PHB concentration $(\boldsymbol{\Delta})$. 


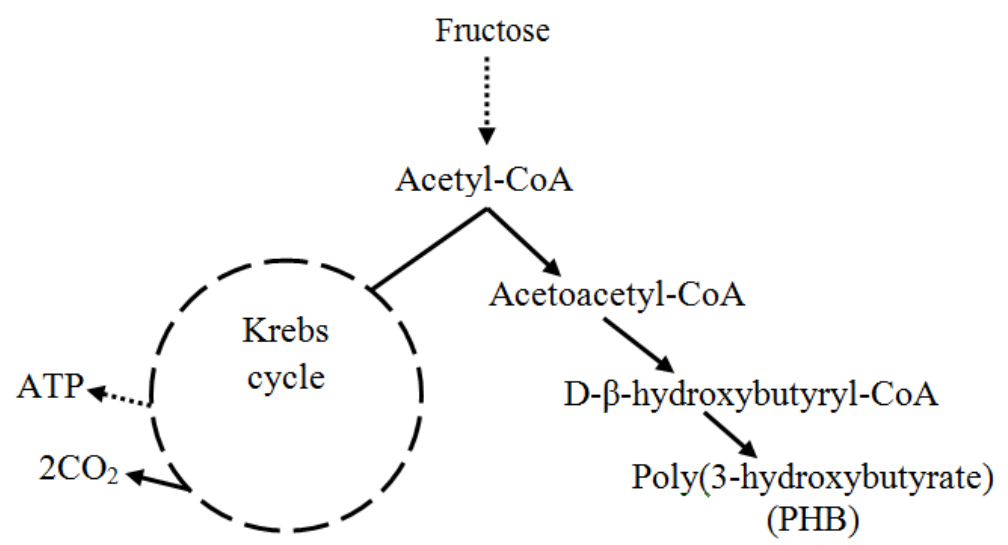

Figure 3. Pathways for ATP production and poly(3-hydroxybutyrate) biosynthesis from fructose (Adapted from Shudesh et al. [2]).

In order to get high CDW, fed-batch fermentation with a modification of fructose feeding strategy was designed. Fructose concentration of around $10 \mathrm{~g} / \mathrm{L}$ was maintained during first stage and then it was increased to around $20 \mathrm{~g} / \mathrm{L}$ during second stage. As showed in Figure 4, CDW was increased and reached maximum value of $45 \mathrm{~g} / \mathrm{l}$ after $34 \mathrm{~h}$ of cultivation, 2.2 folds higher than last fed-batch fermentation $(20.8 \mathrm{~g} / \mathrm{l})$. However, PHB content obtained in this fedbatch fermentation was $46.6 \mathrm{wt} \%$, similar to that obtained in last fed-batch fermentation (45 $\mathrm{wt} \%)$. The results of PHB analysis showed that the synthesis of PHB was still occurred during early stage of cultivation process, PHB content of $25.5 \mathrm{wt} \%$ was reached after $10 \mathrm{~h}$ of cultivation (Figure 4). To avoid that, the concentration of fructose in the culture medium needs to be reduced.

Previous studies have shown that the synthesis of PHA of bacteria can be increased if a nutrient limitation is applied, even with PHA producer bacteria belong to second group (require no such nutrient limitations for PHA synthesis) [4]. For example, Alcaligenes latus is a PHB producer bacterium belonging to the second group, in fed-batch culture under nutrient-sufficient conditions the PHB content obtained was always $50 \mathrm{wt} \%$, however, when nitrogen limitation was applied, the PHB content could be increased to $87 \mathrm{wt} \%$ [10].

Two-stage fed-batch fermentation was then designed: the first stage for biomass production and second stage for PHA accumulation. During first stage (first $18 \mathrm{~h}$ of cultivation) fructose was kept lower than $5 \mathrm{~g} / \mathrm{l}$ and fed solution with nitrogen was added to the bioreactor, fructose concentration was then increased to $20 \mathrm{~g} / \mathrm{l}$ (step by step) and fed solution without nitrogen was used for second stage. Figure 5 showed that during first stage when fructose concentration was low and the requirement nutrient was provided, the synthesis of PHB was inhibited and only about $10 \mathrm{wt} \%$ of PHB was accumulated. PHB content was rapidly increased during second stage (after $18 \mathrm{~h}$ ) and reached maximum value of $67.5 \mathrm{wt} \%$ after $54 \mathrm{~h}$ of cultivation. The results obtained here demonstrated that the accumulation of PHB by this bacterium is very sensitive with the concentrations of carbon and nitrogen sources in the culture medium. High concentration of the carbon source and low concentration of the nitrogen source could trigger the formation of PHB in Yangia sp. ND199.

CDW was increased during fermentation process and achieved maximum value of $78.5 \mathrm{~g} / \mathrm{l}$ after $45 \mathrm{~h}$ of cultivation (10 times higher than that obtained in batch fermentation). The increment of CDW in first stage was mostly due to the increasing of bacterial cells number, but 
it was mainly due to the increment of PHB content in bacterial cells during the second stage. Overall, the maximum PHB productivity of about $1 \mathrm{~g} / \mathrm{l} / \mathrm{h}$ was reached after $45 \mathrm{~h}$ of cultivation. The results obtained from this experiment are comparable with those of the highest reported so far for PHB production by halophilic bacteria. An equivalent of PHB productivity but lower CDW (44 g/L) and higher polymer content ( $81 \% \mathrm{wt})$ were produced by Halomonas boliviensis LC1 using glucose as carbon source [11]. Using open fed batch fermentation, Halomonas TD1 could produce as high as $\mathrm{CDW}$ of $80 \mathrm{~g} / \mathrm{L}$ with higher PHB content of $80 \%$ on glucose [12].

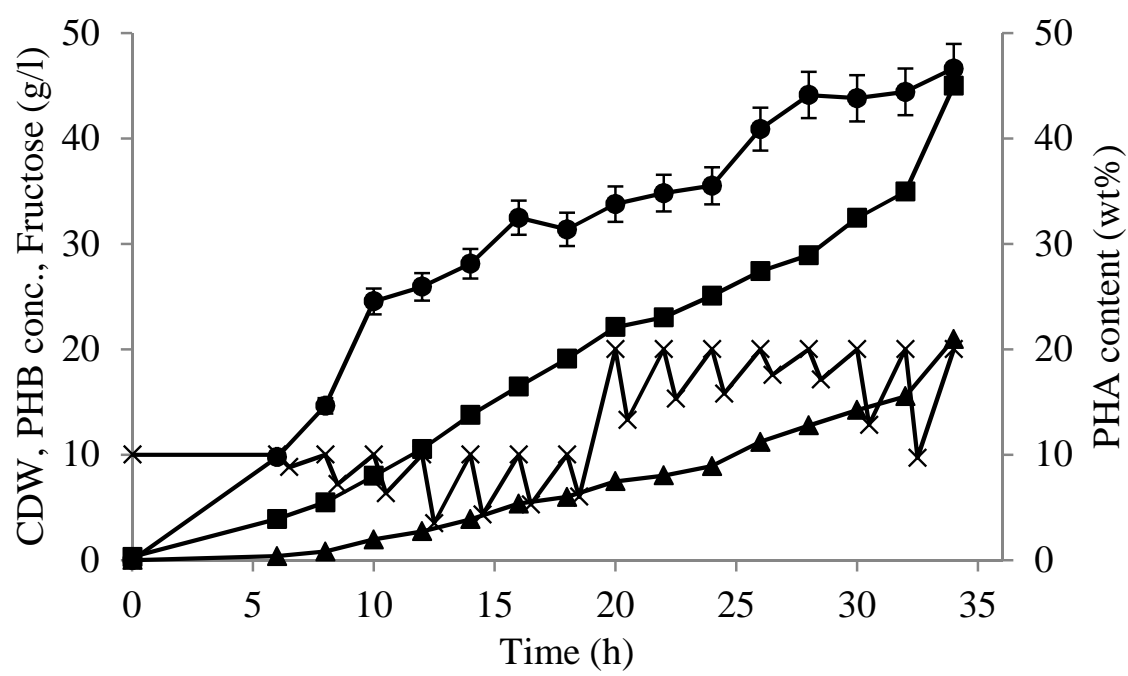

Figure 4. Fed batch cultivation for PHB production by Yangiasp. ND199 with two different fructose concentrations (10 and $20 \mathrm{~g} / \mathrm{l})$. The symbols represent CDW (घ), fructose ( $\times$ ), PHB content $(\bullet)$, and PHB concentration $(\boldsymbol{\Delta})$.

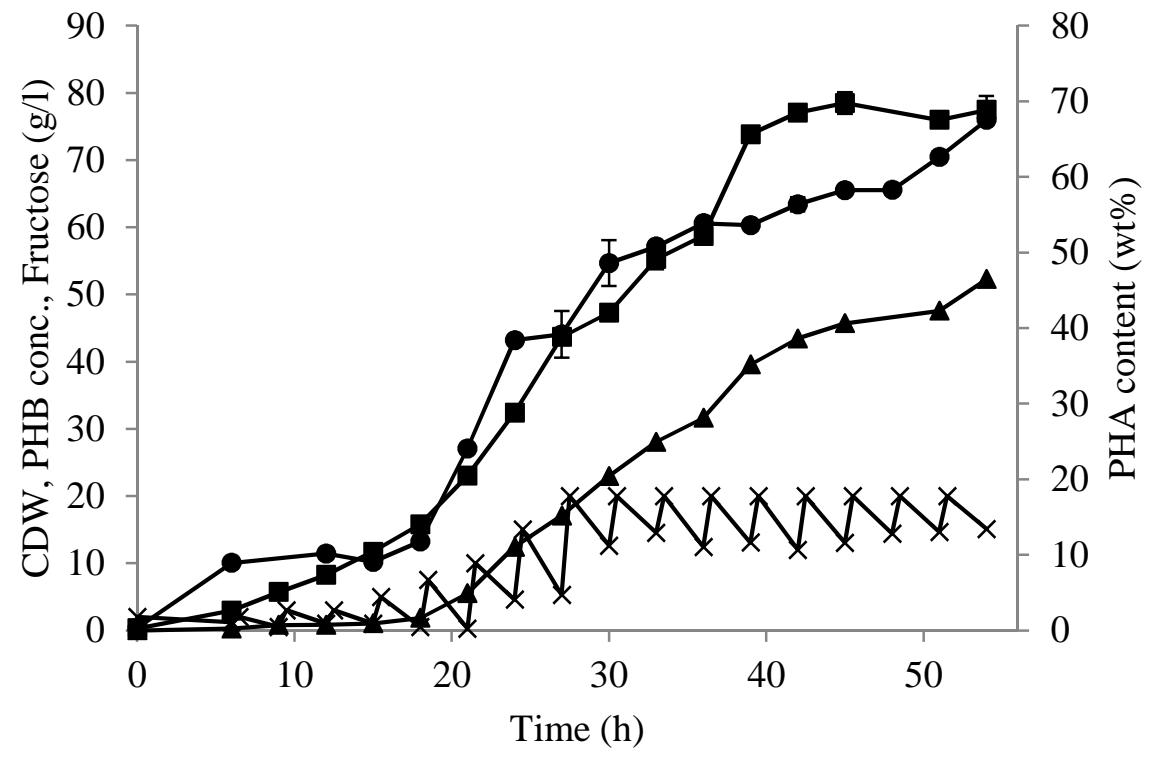

Figure 5. Two-stage fed-batch fermentation for PHB production by Yangiasp. ND199. The symbols represent CDW ( $\boldsymbol{\bullet})$, fructose $(\times)$, PHB content $(\bullet)$, and PHB concentration $(\boldsymbol{\Delta})$. 


\section{CONCLUSION}

The study showed that the strain Yangia sp. ND199 belongs to second PHA producer group that canaccumulate PHB together with cell growth. CDW of $7.8 \mathrm{~g} / \mathrm{l}$ and PHB content of $49 \mathrm{wt} \%$ were achieved in batch fermentation. High CDW of $78.5 \mathrm{~g} / \mathrm{l}$ and PHB content of $67.5 \mathrm{wt} \%$ were obtained by using two-stage fed-batch fermentation in which the first stage was carried out at optimum conditions for bacterial cell growth and the second stage was carried out under the conditions of excess carbon and nitrogen limitation for inducing high PHB accumulation.

\section{REFERENCES}

1. Anderson A. J., Dawes E. A. - Occurrence, metabolism, metabolic role, and industrial uses of bacterial polyhydroxyalkanoates. Microbiol. Rev. 54 (1990) 450-472.

2. Sudesh K., Abe H., Doi Y. -Synthesis, structure and properties of polyhydroxyalkanoates: biological polyesters. Prog. Polym. Sci. 25 (2000) 1503-1555.

3. Lemoigne M. - Produit de déshydratation et de polymérisation de l'acide $\beta$-oxybutyrique. Bull. Soc. Chim. Biol. 8 (1926) 770-782.

4. Lee S. Y.- Bacterial polyhydroxyalkanoates. Biotechnol. Bioeng. 49 (1996) 1-14.

5. Van-ThuocD., Huu-Phong T., Thi-Binh N., Thi-Tho N., Minh-Lam D., Quillaguamán J. Polyester production by halophilic and halotolerant bacterial strains obtained from mangrove soil samples located in Northern Vietnam. MicrobiologyOpen 1 (2012) 395406.

6. Van-Thuoc D., Huu-Phong T., Minh-Khuong D., Hatti-Kaul R. -Poly(3-hydroxybutyrateco-3-hydroxyvalerate) production by a moderate halophile Yangia sp. ND199 using glycerol as a carbon source. Appl. Biochem. Bitechnol. 175 (2015) 3120-3132.

7. Miller G. L. - Use Dinitrosalisilic acid reagent for determination of reducing sugar. Anal. Chem. 31 (1959) 426-428.

8. Huijberts G. N. M., van der Wal H., Wilkinson C., Eggink G.- Gas-chromatographic analysis of poly(3-hydroxyalkanoates) in bacteria. Biotechnol. Tech. 8 (1994) 187-192.

9. SilvaL.F., GomezJ.G. C., OliveiraM.S., TorresB.B.- Propionic acid metabolism and poly3-hydroxybutyrate-co-3-hydroxyvalerate (P3HB-co-3HV) production by Burkholderia sp.. J. Biotechnol. 76 (2000) 165-174.

10. Wang F., Lee S. Y. - Poly(3-hydroxybutyrate) production with high productivity and high polymer content by a fed-batch culture of Alcaligenes latus under nitrogen limitation. Appl. Environ. Microbiol. 63 (1997) 3703-3706.

11. Quillaguamán J., Van-Thuoc D., Guzmán H., Guzmán D., Martín J., Everest A., HattiKaul R. -Poly(3-hydroxybutyrate) production by Halomonas boliviensis in fed-batch culture. Appl. Microbiol. Biotechnol. 78 (2008) 227-232.

12. Tan D., XueY. S., Aibaidula G., Chen G. Q.- Unsterile and continuous production of polyhydroxybutyrate by Halomonas TD01. Bioresour. Technol. 102 (2011) 8130-8136. 